\title{
Unit of Specific Heat Capacity
}

National Cancer Institute

\section{Source}

National Cancer Institute. Unit of Specific Heat Capacity. NCI Thesaurus. Code C69083.

A unit for measurement of the heat energy required to increase the temperature of a unit quantity of a substance by a certain temperature interval (usually by one degree). The specific heat of substances is typically measured under constant pressure or at constant volume. 